\title{
Instâncias de participação na gestão do sistema municipal de ensino: possibilidades \\ e perplexidades no processo de democratização
}

\section{Instances of participation in the management of the municipal system of education: Possibilities and confusion in the process of democratization}

\author{
Edson Francisco Andrade ${ }^{1}$
}

\begin{abstract}
RESUMO
O artigo analisa a questão da construção da cultura democrática no âmbito do sistema de ensino do Recife a partir da inter-relação entre as instâncias de participação envolvidas com a gestão educacional. O estudo contempla, especialmente, o papel dos Conselhos de Educação, assim como as atribuições da Conferência Municipal de Educação (Comude) no processo de proposição de políticas educacionais para os diferentes grupos sociais da sociedade recifense. Os dados foram coletados através de entrevistas semiestruturadas e da administração de questionários em 4 escolas municipais do Recife, além da realização de entrevistas com pessoal estrategicamente posicionado na Secretaria Municipal de Educação, no Conselho Municipal de Educação e membros dos Conselhos Escolares. Palavras-chave: Política educacional; gestão do sistema de ensino; conselhos de educação; Conferência Municipal de Educação.
\end{abstract}

1 Doutorando do Programa de Pós-Graduação em Educação da Universidade Federal de Pernambuco. Atualmente é professor da Universidade de Pernambuco - Campus Garanhuns - Brasil, vinculado ao Núcleo de estudos e pesquisas em Políticas públicas para a educação: avaliação, planejamento e gestão educacional, registrado na instituição, desenvolvendo atividades de pesquisa e extensão universitária, envolvendo, especialmente, as redes de ensino do Agreste Meridional de Pernambuco. 


\begin{abstract}
The article examines the issue of building a democratic culture within the educational system of Recife from the inter-relationship between the parties concerned with the educational administration. The study covers, especially, the roles of Education Boards, as well as the tasks of the Conference Hall of Education (COMUDE) in the process of proposing educational policies to different social groups in Recife. Data were collected through semi-structured interviews and questionnaires on 04 municipal schools in Recife, in addition to conducting interviews with strategically positioned staff at the Municipal Department of Education, the Municipal Council of Education and members of School Councils.

Keywords: Educational policy; management system of education; education boards; Conference Hall of Education.
\end{abstract}

\title{
Introdução
}

Pode-se afirmar que, de maneira geral, a ampliação das formas de participação tem sido o elemento central do debate sobre a gestão pública nos últimos anos. É também cada vez mais perceptível o entendimento de que a intervenção dos diferentes sujeitos sociais envolvidos com os processos educativos deve perpassar não apenas o âmbito da gestão escolar, mas, sobretudo, corroborar as decisões em nível da gestão do sistema de ensino. Nesse sentido, ao mesmo tempo em que se evidencia o fortalecimento de instâncias que pretendem instituir mecanismos democráticos quanto à proposição de políticas educacionais, também se explicita o campo educacional enquanto espaço de disputas pela hegemonia nas instâncias que recebem a incumbência de sistematizar as proposições advindas dos diferentes grupos sociais, e que deverá resultar em políticas públicas válidas para o conjunto da sociedade.

Os estudos que tematizam a gestão em nível dos sistemas de ensino, indicam que o rumo dado à apropriação das possibilidades de descentralização das políticas educacionais, no âmbito do poder local, ainda se confronta com obstáculos de caráter histórico, político e cultural (BITTAR; OLIVEIRA, 2004; CAPANEMA, 2004; KRAWCZYK, 1999). No presente artigo, apresentamos dados de pesquisa realizada no Sistema Municipal de Ensino do Recife (doravante 
SMER), objetivando analisar a questão da construção da cultura democrática, a partir da inter-relação entre as instâncias de participação envolvidas com a gestão educacional ${ }^{2}$.

O SMER dispõe de 214 escolas, 58 creches e 19 escolas profissionalizantes, contemplando mais de 144 mil estudantes matriculados em diferentes níveis e modalidades de ensino, começando pela Educação Infantil (de 0 a 5 anos), que acolhe cerca de 17 mil crianças. No Ensino Fundamental a matrícula é de quase cem mil crianças, e as duas escolas do Ensino Médio contam com aproximadamente 2 mil estudantes. A Educação de Jovens e Adultos (EJA) possui mais de 25 mil estudantes, a maioria em horário noturno. A partir de 2002 a organização do ensino passou a ser por Ciclos de Aprendizagem, distribuídos em conformidade com a seguinte estrutura:
a) Educação Infantil (Creches - 0 a 3 anos e Pré-escola - 4 a 5 anos);
b) Ensino Fundamental - 6 a 14 anos, subgrupados em 4 ciclos;
c) o Ensino Médio e a EJA a partir de 15 anos.

O município realiza o orçamento participativo, constituindo-se um importante espaço de debate e definição das prioridades de investimentos em obras e serviços a serem executados a cada ano com os recursos do Orçamento da Prefeitura. As escolas compartilham diretamente do processo, promovendo plenárias com presença de estudantes e demais sujeitos envolvidos com a educação, na perspectiva de conciliar as demandas por políticas educacionais com o conjunto das necessidades dessa municipalidade.

Os dados foram coletados através de entrevistas e administração de questionários em 4 escolas municipais do Recife ${ }^{3}$, além da realização de entrevistas com pessoal estrategicamente posicionado na Secretaria Municipal de Educação, no Núcleo de Gestão Democrática e no Conselho Municipal de Educação. A constituição do corpus da pesquisa compreende o período das políticas educacionais que se desenvolveram entre 2001 a 2006. Os dados coletados através das entrevistas foram submetidos a um processo de análise de discurso, estabelecendo uma relação entre os depoimentos exteriorizados pelos sujeitos da pesquisa e os elementos que consideramos preponderantes para essa perspectiva de interpretação, a saber: o contexto de produção do discurso, o público a que se destina, os impactos que uma determinada prática discursiva pode provocar no processo tanto de reprodução quanto de mudança social.

2 No contexto mais amplo do sistema de ensino, aplicamos questionários a uma amostra de 78 conselhos escolares, abrangendo as várias Regiões Político-Administrativas da cidade.

3 As escolas que compuseram nosso campo de pesquisa receberam os seguintes codinomes: Escola Verão (EV), Escola Primavera (EP), Escola Outono (EO), e Escola Inverno (EI). 
O sentido em que inferimos a análise do discurso vincula-se à compreensão de que o mundo é criado social e historicamente e, por consequência, são os sujeitos que lhes atribui significados mediante o conjunto das práticas sociais. Nessa perspectiva, a utilização da teoria do discurso como abordagem teóricometodológica não se propõe apenas ao exercício da verificação, refutação e/ou confirmação de um determinado dado da realidade focado num movimento de pesquisa (FOUCAULT, 2007; FAIRCLOUGH, 2001), antes compreende que a própria interpretação da realidade social está intimamente relacionada aos elementos que permitiram sua construção.

Uma questão fundamental norteou a pesquisa: como o sistema municipal de ensino do Recife se organiza para a elaboração e execução de políticas educacionais, considerando-se as atribuições das instâncias de participação mediante a realização de conferências municipais de educação?

Partimos da hipótese de que embora as instâncias de participação atuem em nível da desconcentração da gestão escolar e educacional, ainda assim não intervém efetivamente nas decisões políticas do sistema. Tal postura não contribui para a mudança do paradigma de administração educacional, corroborando com a manutenção da figura da Secretaria de Educação como órgão centralizador do poder de decisão.

O texto é composto por três partes. Na primeira parte, enfocamos as categorias fundamentais que compõe a rede conceitual instituinte do discurso da gestão democrática no campo educacional. Em seguida, discutimos as inter-relações entre as instâncias de participação no que concerne à proposição e execução de políticas educacionais para o Recife. Por último, explicitamos considerações sobre as possibilidades e perplexidades do processo de descentralização no âmbito da gestão do sistema de ensino.

\section{Princípios fundamentais para a gestão democrática do Sistema Municipal de Ensino}

A partir do advento do novo marco legal brasileiro (CF/1988; LDB/96), a formação dos sistemas municipais de ensino passa a ser reconhecida como parte substantiva do processo de democratização da gestão educacional, uma vez que o paradigma sistêmico é concomitantemente inferido enquanto mecanismo de viabilização do processo de proposição de políticas educacionais, tendo como horizonte, a mediação do diálogo entre as instâncias de participação democrática no âmbito do Poder Local. 
Saviani (1999, p. 120), considera que um sistema de ensino significa "uma ordenação articulada dos vários elementos necessários à consecução dos objetivos educacionais preconizados para a população à qual se destina. Supõe, portanto, o planejamento". Tal especificidade com que o termo é internalizado ao contorno educacional, corresponde por um lado, ao pleito de que o "sistema de ensino" não seja concebido como projeção fielmente reproduzida do contexto em que está inserido (o que o reduziria a condição de estrutura), por outro lado, reafirma o propósito de que sua consecução corrobore a constituição da realidade social com que se relaciona.

Assim, é pertinente a menção de que o surgimento do sistema municipal de ensino - SME aparece numa conjuntura em que o município ganha força e expressão autônoma do ponto de vista geopolítico. Portanto, o sistema de ensino apesar de ter sido engendrado em conjunto com a criação dos demais espaços de participação, é somente no momento em que o Município ascende ao nível de ente federado autônomo que o ideário de funcionamento sistêmico passa a ser extensivo, em condições de se atingir sua concretude, no âmbito Municipal.

Por conseguinte, o debate sobre a gestão democrática quer seja em nível escolar, quer seja em nível do sistema de ensino, reclama a consideração de princípios enquanto condição imprescindível à sua materialização. Cabe inicialmente, realçarmos o conceito de democracia que embasa o presente trabalho. Para tanto, inferimos do aporte teórico de Bobbio (1986, p. 18) o entendimento de que se trata de "um conjunto de regras (primárias ou fundamentais) que estabelecem quem está autorizado a tomar as decisões coletivas e com quais procedimentos”. Tal assertiva do autor é consubstanciada com sua percepção de que se faz indispensável à existência de um número de instâncias de participação social nas quais se exerça o direito de voto, resguardando-se na atribuição do poder decisório ao maior número de sujeitos legitimamente eleitos para o exercício da representação da maioria.

Fica posto, portanto, nossa referência ao tipo de democracia representativa como opção plausível ao atual contexto de relações que se vislumbra na gestão pública. Contudo, o significado de democracia representativa não é correlato ao oposto de democracia direta, conforme ressalta Bobbio (1986, p. 52), "isto implica que, de fato, democracia representativa e democracia direta não são dois sistemas alternativos (no sentido de que onde existe uma não pode existir a outra) mais são dois sistemas que podem integrar reciprocamente”. Esse argumento é compreendido ao observarmos que o exercício da democracia representativa é oxigenado pela democracia direta na medida em que admite que os representantes sejam substituíveis.

O importante é que a democracia representativa ganhe concretude por meio da criação de novos espaços na esfera pública, constituindo-se um cami- 
nho alternativo aos órgãos do tipo estritamente hierárquico ou burocrático que tradicionalmente compusera a estrutura administrativa estatal. Assim, pode-se mencionar a participação, a descentralização/ desconcentração e a autonomia como pertencentes a uma rede conceitual que constitui a formação discursiva, a partir da qual se toma como referência analítica à gestão democrática no campo educacional e que, oportunamente, trataremos a seguir.

\section{O princípio da Participação Social}

O tema da participação tem sido tratado historicamente à luz de uma ampla perspectiva de entendimento. Algumas das acepções com que esse vocábulo é empregado (a liberal, a autoritária, a revolucionária e a democrática), apesar de já serem consideradas clássicas, vêm sofrendo inflexões em função do foco que mobiliza sua inferência nas práticas discursivas e sociais, sobretudo àquelas que constituem mecanismo de implementação da ação estatal.

A prerrogativa da ressignificação do termo "participação", no contexto da administração pública, tem sido interpretada como estratégia do grupo que exerce a hegemonia na gestão estatal com vista ao "gerenciamento" da participação dos sujeitos sociais nas instâncias de poder decisório. É propriamente referindo-se a esse fenômeno que Demo (1991, p. 101) desenvolve a assertiva de que "o poder não pode chegar a seu destino como poder; por isso, com freqüência, usa a capa da participação. Este é o seu melhor disfarce. Quando a imposição é aceita como forma de participação, temos o poder hábil, estratégico, capaz”.

A observação do autor é emblemática para a apreensão do termo em sua amplitude polissêmica. Com efeito, pode-se encontrar a utilização do termo com o sentido de cooptação de indivíduos mediante a promoção de programas que visam apenas diluir os conflitos sociais, tratando-se, portanto, de uma concepção de participação da sociedade civil divorciada da intervenção na proposição das políticas, e apenas circunscrita à função de provedora de serviços.

Contudo, a participação também expressa o fortalecimento da sociedade civil na perspectiva da definição, acompanhamento e avaliação da ação estatal. Esse ideário corresponde à acepção de participação realçada e assumida por Demo (1991), ao concebê-la enquanto processo histórico de conquista das condições de autodeterminação. Esse é um movimento que não se empreende pela via da imposição. Segundo o autor, "participação existe, se e enquanto for conquistada. Porque é processo, não produto acabado” (DEMO, 1991, p. 101).

Dessa feita, evidencia-se a participação política como processo relacionado ao número e a intensidade de indivíduos envolvidos na tomada de decisões no espaço público. Nossa ênfase conceitual neste trabalho atenta para essa última dimensão, resguardando-se no ideário da participação como estratégia de ação 
política dos sujeitos sociais com vista à democratização da gestão pública. Logo, conciliamos com Habermas (apud GUTIERREZ; CATANI, 2003), no que diz respeito à sua concepção de que participar significa que todos podem contribuir, com igualdade de oportunidades, nos processos de formação discursiva da vontade, ou seja, participar consiste em ajudar a construir comunicativamente o consenso quanto a um plano de ação coletivo.

Faz-se importante mencionar que ao conceber a possibilidade da atuação dos sujeitos sociais nos espaços públicos, sendo em nosso caso, particularizado o campo educacional, estamos, ao mesmo tempo, enfatizando a necessidade de se romper com a lógica de uma participação planejada e regulada pelo Estado. Assume-se aqui, por coerência de princípio, que "a tomada de consciência da necessidade de decidir e o posterior processo de decisão, quando feito no coletivo, propicia a riqueza de idéias, o debate, o confronto de argumentos diferentes que se constroem no próprio processo coletivo de consciência do problema em questão” (FERREIRA, 2004, p. 312).

Seguindo esse juízo, o ato participar pressupõe mediação discursiva entre o Estado e a sociedade civil, constituindo-se processo de construção de normas e procedimentos que vão nortear o jogo democrático, do qual todos os sujeitos coletivos compartilham desde a proposição, perpassando a materialização e o controle social do conjunto de políticas que expressam a dinâmica do Estado em ação.

\section{O Princípio da Descentralização}

Assim como a participação, a descentralização tem se constituído, além de um dos princípios da gestão democrática, uma categoria de análise da dinâmica de elaboração e execução de políticas públicas no setor educacional. Merece consideração o fato de que o princípio/categoria descentralização tem sido tratado como um tema complexo e ambíguo, uma vez que, por um lado, é utilizado com a conotação de desconcentração, assegurando a eficácia do poder central, quando transfere responsabilidades para o nível local e exerce a função de regulação, garantindo, através de sua posição hierárquica, o controle dos resultados. Por outro lado, o termo demonstra uma acepção democráticoparticipativa, expressando maior intervenção das instâncias locais nas decisões tomadas em nível de sistema de ensino. Sendo assim, é oportuna a colocação de Casassus (1995, p. 95), quando diz que "ao transferir competências, há de se pensar que é necessário reacomodar situações tanto do ponto de vista de quem recebe a competência quanto do ponto de vista de quem se desprende dela”.

Portanto, em face de se tratar de um tema que admite a coexistência de relações que não se dão em qualquer lugar, mas dentro de um sistema de ensino, 
a ação descentralizadora reclama a participação dos sujeitos sociais no processo de definição das políticas educacionais, além do reconhecimento da autonomia como valor intrínseco e indispensável à prática democrática entre as instâncias que compartilham dos espaços decisórios.

\section{O Princípio da Autonomia}

A noção de autonomia é aqui inferida como um construto que necessariamente congrega o interesse do coletivo nos processos de definição das regras que orientam o jogo democrático na gestão educacional. No que concerne ao marco legal, merece destaque os artigos 206 da Constituição Federal (BRASIL, 1988) e 14 e 15 da LDB (BRASIL, 1996) que passa a referenciar progressivos graus de autonomia às unidades de ensino como uma das premissas da democratização no espaço público, especialmente no campo educacional.

Torna-se premente a reafirmação de que as escolas precisam se certificar da necessidade de se pensar a vivência da autonomia como consequência de seus próprios esforços; de suas reflexões no sentido da elaboração de um Projeto Político-Pedagógico que aponte para o atendimento das especificidades de cada realidade escolar. Nessa afirmação, estamos tão somente enfatizando a noção de autonomia construída por aqueles que a desejam e, evidentemente, nos afastando da adoção de uma postura passiva em que circunscreve a autonomia como decreto em leis, ou concessão das autoridades governamentais que representam o Estado.

Nesse sentido, a autonomia constitui e é constituída como prática político-pedagógica, prática essa cujo foco central é o próprio fortalecimento das instâncias cogestoras do sistema de ensino. Contudo, consideramos pertinente ressaltar, em concordância com Barroso (2003, p.17) que "autonomia é um conceito relacional (somos sempre autônomos de alguém ou de alguma coisa) pelo que a sua ação se exerce sempre num contexto de interdependência e num sistema de relações”.

Com efeito, procuramos aceitar a concepção de autonomia que tem como pressuposto a inter-relação entre as instâncias do sistema; que reconhece o exercício da autonomia como construção que perpassa à tensão genuína das relações democráticas. Por isso, a prática da autonomia não pode e nem deve ser autorreferente, mas referente ao contexto do sistema educativo do qual a escola é parte constituinte, e ao contexto social, político, econômico e cultural, no qual não apenas a escola está inserida, mas o próprio sistema de políticas educacionais. 


\section{O contexto das relações entre as instâncias de participação do Sistema de Ensino do Recife}

O Sistema Municipal de Ensino do Recife - SMER foi criado pela Lei Municipal No 16.768/2002, cujos órgãos, na forma dessa Lei, devem exercer as funções de planejamento, organização, implantação e execução de políticas e planos educacionais, em consonância com as diretrizes e planos nacionais e estaduais de educação. A organização, assim como a natureza das atribuições do SMER inspira-se nos princípios da gestão democrática, uma vez que preceitua a inter-relação entre as instâncias de participação (Secretaria Municipal de Educação; Conselho Municipal de Educação - CME; Escolas Públicas Municipais de Ensino Fundamental; Instituições de Educação Infantil mantidas pelo Poder Público Municipal e pela iniciativa privada; Escolas Públicas Municipais de Ensino Médio) como prerrogativa de sua atuação.

Não obstante, ao indagarmos os conselheiros escolares sobre a intensidade de suas relações com as demais instâncias do SMER tivemos reiteradamente a resposta de que a ausência de uma instância de interlocução constitui um agravante significativo da frágil comunicação entre os conselhos escolares e também da relação desses com o conjunto do sistema de ensino. Os dados quantitativos confirmam, expressivamente, a desarticulação entre os colegiados escolares, impedindo tanto a prática dialogal em nível de cada Região Político-Administrativa - RPA da cidade, como o momento de discussão de acordos com o CME.

Sobre esse aspecto, observa-se que apenas $20,5 \%$ dos 78 conselhos escolares consultados conseguem articular-se com outros conselhos da mesma RPA. Esse dado evidencia as dificuldades para o fortalecimento da ação colegiada para além dos limites da escola. Situações como a definição do calendário escolar, considerando-se não apenas a distribuição dos dias letivos, mas, sobretudo a agenda da educação municipal para um determinado período letivo; a discussão sobre a formação continuada dos professores; a elaboração da matriz curricular que referencia a base comum, assim como os conteúdos programáticos e situações didáticas que atendam as demandas locais; reivindicação de melhores condições objetivas para o processo de ensino-aprendizagem nas unidades de ensino municipais, dentre outras, exigem uma ação integrada das instâncias de participação, sobretudo entre as próprias unidades de ensino.

Nesse mesmo sentido, indagamos se o conselho escolar tem comunicado suas decisões a outras instâncias do SMER. Os conselheiros escolares de 52,6\% das unidades de ensino pesquisadas revelam que raramente comunicam suas decisões. Ao pontuarem os poucos momentos dessa comunicação, fazem men- 
ção às requisições da Secretaria de Educação e/ou do CME. Não são momentos efetivos de compartilhamento de decisões. Além disso, 23,1\% das escolas declaram que não comunica nenhuma decisão ou proposta às demais instâncias cogestoras da educação municipal.

Na realidade, ao correlacionarmos os dados apresentados ao longo de nosso trabalho, identificamos um quadro em que o discurso da gestão democrática se restringe provavelmente, ao nível dos textos elaborados pelos sujeitos que respondem pelas instâncias superiores do sistema de ensino. Não obstante, assim como a literatura tem tratado vastamente, numa gestão democrática, as ações, os atos e os princípios são decididos e assumidos coletivamente por todos os sujeitos envolvidos com a gestão educacional.

Por estarmos considerando a constituição dos sistemas municipais de ensino como um importante mecanismo de democratização da educação, é que reafirmamos o interesse em difundir o modo como tais sistemas têm se organizado e operado, mesmo sem desconhecer que nos espaços locais, assim como no contexto mais amplo do País, têm-se, ainda, práticas políticas voltadas para a perpetuação do clientelismo e do patrimonialismo. Nesse âmbito, passaremos à análise sobre o papel da Conferência Municipal de Educação, ressaltando a relevância dessa instância enquanto mecanismo de participação coletiva no processo de proposição de políticas educacionais, que segundo a Lei Municipal $\mathrm{n}^{\mathrm{o}} 16.768 / 2002$, deve contemplar a presença de todos os segmentos da educação municipal do Recife.

Conferência Municipal de Educação: limites e possibilidades para a proposição de políticas educacionais

A Conferência Municipal de Educação - Comude - constitui o principal espaço de discussão entre as instâncias de participação da gestão educacional do Recife. Apesar de seu caráter não ser deliberativo, suas proposições devem subsidiar as decisões da Secretaria de Educação e orientar o trabalho do CME em sua tarefa de acompanhamento e avaliação das políticas que serão efetivadas em nível do sistema municipal de ensino.

Há convergências entre os depoimentos de que a realização da Comude contribui para a socialização de experiências entre as comunidades escolares das seis regiões político-administrativas da cidade, favorecendo o debate sobre os principais assuntos da agenda educacional recifense, além de instigar ações coletivas em defesa da melhoria da qualidade da educação pública do município. Entretanto, observamos que seu caráter não deliberativo, provoca uma sensação de que as discussões, ali promovidas, não têm nenhuma garantia de que irão, efetivamente, ser implementadas pela gestão. 
A opinião de parte significativa dos sujeitos da pesquisa, especialmente os que são vinculados diretamente às escolas, é de que a Comude deveria assumir caráter deliberativo. Além disso, os entrevistados também ressaltaram a necessidade do poder público fazer saber as suas apreciações sobre a conferência, no que diz respeito tanto às proposições que podem ser implementadas, quanto às propostas que o governo precisa justificar as razões pelas quais não poderá ser materializada no âmbito da educação municipal. Assim, é relevante salientamos o contexto em que as propostas são elaboradas, assim como as condições para que sejam incorporadas às políticas do setor educacional. Em relação a esse último aspecto, merece menção o fato de que os resultados da Comude deverão ser analisados conjuntamente com outras propostas defendidas pelos demais setores que integram a gestão do município. Dessa feita, o trâmite que se desenrola após a conferência, exige a presença dos sujeitos envolvidos com a educação para que as novas correlações de força não releguem a segundo plano o que inicialmente foi proposto.

O fato é que nós já identificamos que as instâncias de participação funcionam desarticuladamente, assim, o processo de compartilhamento das decisões que deveria seguir as orientações da Comude se restringe aos consensos entre as gerências que integram a administração municipal. Além disso, tem-se o descaso do governo municipal com as propostas que emanam da conferência. O depoimento do ex-secretário adjunto de educação ajuda-nos a comentar esse item.

Eu acho que você reúne a sociedade, chama pra conversar, ainda que não seja para vincular o que você vai fazer, é obrigação do poder público dá retorno. Também em que medida você combina resoluções da conferência com resoluções de plenárias temáticas do Orçamento Participativo? Então, às vezes você tem, assim, dito no bom sentido, um excesso de participação sem construções de canais que vão dá seqüências ao que sai da participação.

Esse entrevistado alude uma preocupação enfaticamente reiterada por outros sujeitos da pesquisa, quanto ao desdobramento das negociações do que foi proposto na conferência. A esse respeito, pudemos constatar que, para os sujeitos da escola, a Comude se resume ao seu período de realização. Isso significa que nem a preparação, nem tampouco o acompanhamento das propostas são atividades que incluem a participação do conjunto das instâncias do sistema de ensino.

Interessa-nos discutir o que pensam os entrevistados sobre os resultados da Comude. Algo que também nos chama a atenção é a forma como os sujeitos 
da pesquisa percebem o processo de sistematização das propostas. O testemunho da representante dos pais da Escola Primavera realça esse último aspecto:

eu acho que pelo caminhar é a própria Secretaria quem decide. Eu acho que seria papel nosso, do conselho, ir lá fiscalizar, cobrar. Mas, como não acontece isso, eles também não repassam. Eu acho, também, que pra eles não é viável repassar, porque jamais eles repassam o que foi feito, o que a gente cobrou. Eu acho que tudo é decidido lá.

O argumento dessa representante dos pais da Escola Primavera faz alusão ao fato de que a Secretaria de Educação não considera as propostas encaminhadas ao final da Comude, ou seja, as deliberações que passam a constituir as políticas educacionais do município não correspondem, necessariamente, ao que foi discutido ao longo da conferência. Trata-se, na voz dessa entrevistada, de decisões que refletem as opções políticas da Secretaria de Educação. Sobre esse assunto, a conselheira ainda ressalta que os conselheiros escolares não assumem uma postura reivindicativa no que se refere à solicitação para que o relatório dos resultados da Comude possa ser socializado e, consequentemente, viabilize o acompanhamento de sua implementação.

Já o depoimento do Técnico Educacional que integra a equipe de gestão faz um tipo de recorte dos resultados das conferências, deixando refletir sua missão de suporte à Secretaria de Educação.

Em 2004, a gente vê muita coisa realizada, coisa grandiosa. A regulamentação da COMUDE; os Ciclos de Aprendizagem [...] Mas aí, os professores já sentiram que esse é o caminho, agora queriam discutir os mecanismos pra melhorar o processo de implantação. Não como uma rejeição a essa proposta, mas pra aperfeiçoar isso, e querer um acompanhamento. O planejamento estratégico da prefeitura contempla muito das propostas. Quando a gente vai ver, essa é a sensação que eu tive:_Ah!... O planejamento está em consonância com as proposições da conferência!

Esse mesmo depoente quando comenta os resultados das conferências, a partir do nosso questionamento sobre o desempenho dos conselheiros escolares, faz a seguinte colocação: 
se você for analisar o saldo das proposições, elas foram muito para o emergencialismo que é o retrato da voz da escola. Então, é a dinâmica da escola, não é. Foi com essa dinâmica que a gente enfrentou a IV Conferência. Na V, já dá um salto maior, porque ela já tinha um objetivo direcionado, além das questões temáticas, tratava do Plano.

Há nos argumentos desse representante da Secretaria de Educação um ajuste em conformidade aos contextos a que se dirigem. A Comude, sob o ponto de vista do desempenho da gestão (Referindo-se especialmente à Secretaria de Educação), é uma coisa grandiosa. Mesmo o episódio da implantação dos Ciclos de Aprendizagem, fato que conforme constatamos, 85,9\% dos conselhos escolares declaram nenhuma participação no processo de discussão e implantação na Rede Municipal de Ensino, aparece no discurso do Técnico Educacional como que constasse na pauta de discussão.

Quando esse entrevistado faz referência à escola, seu destaque é para a limitação dos conselheiros quanto as suas proposições voltadas para o emergencialismo. A impressão que se quer passar é que na Comude, como em todos os processos que os conselhos escolares figuram, suas contribuições sempre estão aquém de um debate em bom nível sobre a gestão educacional do município - argumento que serve inclusive para justificar a inconsistência dos diálogos entre a escola e o centro do sistema de ensino.

Ressaltamos as condições em que ocorre a Comude em face da sua importância para o planejamento de melhorias na promoção da educação pública no município do Recife. Chegamos à conclusão que esse espaço tem favorecido o diálogo entre os sujeitos envolvidos com a educação recifense, entretanto, é preciso corrigir as graves falhas que se estendem desde a preparação do evento até o processo de sistematização e socialização dos resultados, incluindo-se a definição de um cronograma de atividades que contemple encontros com conselheiros escolares para fortalecerem a dinâmica de acompanhamento das propostas em outros espaços de discussão.

\section{Considerações Finais}

Propusemo-nos, neste trabalho, analisar como o SMER se organiza para a elaboração e execução de suas políticas educacionais, considerando-se, de forma imprescindível, as práticas discursivas e sociais entre as instâncias cogestoras 
da educação municipal. A esse respeito, destacamos as atividades da Comude enquanto iniciativa mais importante do governo municipal, sobretudo porque seu funcionamento favorece as contribuições das instâncias de participação quanto à discussão das normas e medidas a serem implementadas pelas escolas municipais. Entretanto, não observamos, nas relações estabelecidas entre as instâncias de participação, uma prática dialogal sistemática capaz de permitir a manifestação dos pontos de vista do conjunto dos segmentos que compõe o sistema municipal de ensino.

Assim, os dados analisados indicam que embora as instâncias de participação atuem em nível da desconcentração da gestão escolar e educacional, ainda assim não intervém efetivamente nas decisões políticas do sistema de ensino. Evidenciam essa realidade os dados que apontam a gestão financeira como principal atividade dos conselhos escolares ao longo dos cinco anos desse governo, enquanto que as principais decisões no âmbito político-pedagógico foram tomadas sem que houvesse uma discussão com os sujeitos vinculados às escolas.

Quando nos referimos à Comude, temos ainda mais razões para destacarmos as desigualdades nas condições de participação. Em nosso estudo, chamamos a atenção para esse encontro, considerando-o como evento mais importante da agenda da gestão educacional do município do Recife. Entretanto, constatamos a grave desarticulação quanto a seu planejamento, execução e, sobretudo, sistematização de seus resultados.

No que concerne a gestão educacional do município, conclui-se que a desarticulação entre as instâncias de participação constitui a principal causa da centralização do poder de decisão sob a égide da Secretaria de Educação. Isso prova que a dificuldade de participação que frequentemente é apontada como limitação estritamente da escola, trata-se de um problema que envolve, sobretudo, os órgãos de maior poder decisório do sistema de ensino.

Assim, entendemos que o atual organograma da gestão educacional, em que se verifica a postura da Secretaria de Educação como centro do sistema de ensino, em detrimento do papel periférico exercido pelas demais instâncias de participação, precisa ser repensado, considerando-se a necessidade de ativação dos mecanismos de interlocução no interior do sistema como principal contrapartida em favor do avanço no processo de construção da cultura democrática na gestão do sistema municipal de ensino.

A esse respeito, propomos um movimento entre as instâncias de participação que expressa a ideia da decisão compartilhada, enfatizando-se o princípio da descentralização do poder de decisão como premissa das relações estabelecidas. Nesse perfil de relacionamento sistêmico, os conselhos escolares socializam suas concepções ao se representarem nas Comissões Regionais de Educação. 
Essas comissões não devem se constituir apenas pelos próprios conselheiros escolares. Faz-se necessário à presença de membros do conselho municipal de educação, inclusive como prerrogativa de escolha dos representantes para essa instância. A dinâmica de relações entre as comissões regionais e CME pretende fortalecer o caráter representativo da democracia, sem com isso prescindir da participação da base do sistema.

Sendo assim, as práticas cotidianas do CME, na sua relação com a Secretaria de Educação, refletem, necessariamente, às proposições das comissões, que por sua vez contempla as discussões que ocorrem no interior das instituições escolares. A realização da Comude se insere nessa relação como momento em que os sujeitos envolvidos com a educação municipal propõem as políticas educacionais à luz de suas conviç̧ões amadurecidas ao longo de uma sistemática de trabalhos que contempla uma agenda de atividades anteriores à conferência.

É evidente que os desafios à implementação desse paradigma de relacionamento no interior do sistema são muitos e reclamam a iniciativa de todas as instâncias, não apenas a contrapartida das instâncias periféricas, conforme observamos o papel dos conselhos escolares no contexto atual. Assim, a existência de instâncias superiores, tal qual precisamos retratar a Secretaria de Educação e o Conselho Municipal de Educação ao longo deste texto, em função de ser esse o perfil atual dessas instâncias, destitui-se. Por conseguinte, o modelo de relacionamento no sistema que estamos propondo, ampara-se na concepção de horizontalidade entre os participantes da ação comunicativa.

\section{REFERÊNCIAS}

BARROSO, J. O reforço da autonomia das escolas e a flexibilização da gestão escolar em Portugual. In: FERREIRA, N. S. Carapeto (Org.). Gestão Democrática da Educação: atuais tendências, novos desafios. São Paulo: Editora Cortez, 2003.

BITTAR, M.; OLIVEIRA, João F. Gestão e Políticas da Educação. Rio de Janeiro: DP\&A, 2004.

BOBBIO, N. O futuro da democracia: uma defesa das regras do jogo. 5. ed. Rio de Janeiro: Paz e Terra, 1986.

BRASIL. Constituição da República Federativa do Brasil. Brasília, 1988.

BRASIL. Lei $n^{\circ}$ 9.394, de 20 de dezembro de 1996. Estabelece as Diretrizes e Bases da Educação Nacional, 1996. 
CAPANEMA, C. F. Gênese das mudanças nas políticas públicas e na gestão da educação básica. In: BITTAR, M.; OLIVEIRA, J. F. Gestão e políticas da educação. Rio de Janeiro: DP\&A, 2004.

CASASSUS, J. Tarefas da Educação. Campinas, São Paulo: Autores Associados, 1995.

CATANI, A. M.; GUTIERREZ, G. L. Participação e gestão escolar: conceitos e potencialidades. In: FERREIRA, N. S. C. (Org.). Gestão Democrática da Educação: atuais tendências, novos desafios. São Paulo: Editora Cortez, 2003.

DEMO. P. Pobreza Política. 3. ed. Campinas/SP: Autores Associados, 1991.

FAIRCLOUGH, N. Discurso e mudança social. Brasília: UNB, 2001.

FERREIRA, N. S. C. Gestão Democrática da Educação: ressignificando conceitos e possibilidades. In: FERREIRA, N. S. C.; AGUIAR, M. A. da S. Gestão da Educação: impasses, perspectivas e compromissos. 4. ed. São Paulo: Cortez, 2004.

FOUCAULT, M. Arqueologia do saber. 7. ed. Rio de Janeiro: Forense Universitária, 2007.

KRAWCZYK, N. A gestão escolar: um campo minado... Análise das propostas de 11 municípios brasileiros. Educação e Sociedade, Campinas, v. 20, n. 67, 1999. Disponível em: <http://www.scielo.br/pdf/es/v20n67/v20n67a04.pdf> Acesso em: 27/10/2008.

RECIFE. Lei $N^{o}$ 16.768/2002. Cria o Sistema Municipal de Ensino do Recife - SMER. Promulgada em 3 de Maio de 2002. Recife, 2002.

SAVIANI, D. Sistemas de ensino e planos de educação: o âmbito dos municípios. Educação e Sociedade, Campinas, v. 20, n. 69, 1999. Disponível em: <http://www. scielo.br/scielo > Acesso em: 27/10/2008.

Texto recebido em 10 de novembro de 2008.

Texto aprovado em 4 de fevereiro de 2009. 